\title{
Studies on Disability Perspectives Inclusive Education in Nepal - Focus on Methodological Review
}

\author{
Kiran Chalise \\ School of Education, Kathmandu University, Hattiban, Lalitpur, Nepal \\ Received October 18, 2020; Revised January 12, 2021; Accepted January 20, 2021
}

\section{Cite This Paper in the following Citation Styles}

(a): [1] Kiran Chalise, "Studies on Disability Perspectives Inclusive Education in Nepal - Focus on Methodological Review," Universal Journal of Educational Research, Vol. 9, No. 3, pp. 441-448, 2021. DOI: 10.13189/ujer.2021.090303.

(b): Kiran Chalise (2021). Studies on Disability Perspectives Inclusive Education in Nepal - Focus on Methodological Review. Universal Journal of Educational Research, 9(3), 441-448. DOI: 10.13189/ujer.2021.090303.

Copyright $\mathrm{C} 2021$ by authors, all rights reserved. Authors agree that this article remains permanently open access under the terms of the Creative Commons Attribution License 4.0 International License

\begin{abstract}
Disability has three major perspectives; the bio-medical; functional and right-outcome [1]. From this angle, the concern of the study in the form of any perspectives and its results are always the curious part for the people and scholars who are investing their time to contribute to the field of inclusive education and disability in Nepal. Under this context, this study is the review of the available studies on disability perspectives inclusive education happened in Nepal from the period of 2010 to 2020. It is basically the methodological description/ review with major findings on the compiled studies. For the study, the researchers, studies, books, reports and journal articles published and issued in Nepal and carried out in the context of Nepal particularly on disability perspectives inclusive education were compiled and reviewed. The descriptive analysis showed that majority of studies were carried out from subjective analysis domination (qualitative) rather than objective (quantitative) ones by excluding the analysis to know on what extends the atmosphere of schools will hamper the education of disabled children in schools. The problems and challenges to implement inclusive education were not minutely revealed out by the studies through the set quality indicators of inclusive education in Nepal. The study has suggested initiating the researches on mentioned angles in research gaps.
\end{abstract}

Keywords Persons/Children with Hearing Impairment, Disability, Inclusive Education, Details of the Studies (Table 1)

\section{Introduction}

Education including all other fundamental rights is the rights of every child/citizen regardless of their gender, caste, ethnicity, race, disability and any forms of vulnerability. It has been guaranteed by the constitution of Nepal, 2015 [2]. Similarly, the United Nations Convention on the Rights of Persons with Disabilities (CRDP), 2006 has special provision for the persons with disabilities and children. These all provisions and entitlements are focused on ensuring the fundamental rights of persons/children with disabilities [3].

In the context of ensuring the rights, different sectors' roles and responsibilities are always in paramount importance. The state functionaries including academic and non- academic/social sectors should work together to ensure the rights of persons/children with disabilities. These sectors can at least contribute from their sides to gathering the information and revealing out the situation of such persons/children to contextualize the situation and recommend for proper considerations to ensure their fundamental rights.

In gathering the information and revealing out the situation, there is always the need of proper studies. When we talk about the studies, the methodological aspect will always come in mind. It is a common belief that the methodological approach will always contribute to enriching the findings of the studies so that the concerned sectors and groups will be benefited effectively.

It is a general perception that there is a lack of adequate investigative researches and practices (Academic and 
non-academic) on disability and inclusive education in Nepal. There is a lack of adequate investigative researches and practices for disable friendly evaluation, exam systems, and learning management of disabled students in Nepal [4].

The minimum studies on disability perspectives inclusive education could be one of factors to minimize the better education of children with disabilities in Nepal. However, this has not been checked and figured out exclusively. How many studies (researchers, investigations, reports, books, journals etc.) were published in Nepal from disability perspectives inclusive education? What were the findings of such studies, what were the methodological approaches on such studies? and what are the research gaps on disability perspectives inclusive education in Nepal? Are some of the questions which are not dealt with appropriately.

Thus, the intent of this paper was to review basically the methodological approaches of available published/issued 'disability perspectives inclusive education based studies (researches, reports, books, journals) from the period of 2010 to the date in Nepal. The purpose of this descriptive method was to obtain qualitative and quantitative results of such studies from its methodological approaches thereby reveal out the research gaps in disability perspectives inclusive education in Nepal for further studies in the area of disability and inclusive education.

\section{Research Methods and Approach}

With the above context, I developed a research project to answer the following research questions:

1. What are the methodological approaches of the studies published/issue so far in Nepal from disability perspectives inclusive education?

2. What are the research gaps of these published studies from inclusive education and disability point of view?

In order to find out above issues, first I collected/compiled available studies of the time period based on inclusive education and persons/children with disabilities and education by visiting libraries, inquiring to the experts of inclusive education and disability, scholars/students studying and doing researches in disability and inclusive education, searching via search engines.

There were basically three bases (Disability and education, Persons/Children with disabilities and education, and inclusive education of children with disabilities) for the collection of the studies.

The major purpose of determining the categories was to ensure maximum no. of studies in the field of disabled focused inclusive education. After collecting all the studies of the mentioned time period, the documents were tabularized in the form of title, category (academic research, non-academic research, report, book, and journal), study area, method/approach, author/writer, institution, publisher, and published year. The major findings of each study were also captured from the documents to explore the research gaps in the area of disabled focused inclusive education. Each of the categorized form of the documents was checked and inserted the information accordingly in SPSS. According to the acquired information, the studies were reviewed from the angle of their methodologies and the findings in descriptive analysis.

\section{Results and Discussion}

In the table 1, the details of studies in terms of area, types, approaches, paradigms/traditions and designs are presented. After searching, a total of 31 studies were found in the study theme. Basically the studies were rounded up on the themes as inclusive education, children with disabilities, disability and education sector. It has been found that children with disabilities related studies were in higher number (12) when compiling the studies on disability perspectives inclusive education in Nepal.

Table 1. Details of the Studies

\begin{tabular}{|c|c|c|c|c|c|c|c|}
\hline \multicolumn{2}{|c|}{} & \multicolumn{2}{c|}{$\begin{array}{c}\text { Details of qualitative approach of } \\
\text { academic level research }\end{array}$} & \multicolumn{2}{c|}{$\begin{array}{c}\text { Details of quantitative } \\
\text { approach of academic } \\
\text { level research }\end{array}$} & \multicolumn{2}{c|}{$\begin{array}{c}\text { Study design of } \\
\text { academic level } \\
\text { researches }\end{array}$} \\
\hline Qualitative & 18 & Ethnographic & 1 & $\begin{array}{c}\text { Post positivist } \\
\text { (Survey) }\end{array}$ & 3 & $\begin{array}{c}\text { Convergence } \\
\text { parallel }\end{array}$ \\
\hline Quantitative & 6 & Interpretive & 4 & & Descriptive & 1 \\
\hline Mixed & 7 & Pragmatic & 1 & & $\begin{array}{c}\text { Descriptive \& } \\
\text { inferential }\end{array}$ & 2 \\
\hline Total & & Social constructivist & 1 & & Explanatory & 3 \\
\hline & & $\begin{array}{c}\text { Social constructivist and } \\
\text { interpretive }\end{array}$ & 1 & & Exploratory & 5 \\
\hline Total & 31 & Transcendental & 1 & & \\
\hline
\end{tabular}


Similarly in types of studies, the journal articles were in higher (7) number followed by reports (6) and academic research of $\mathrm{PhD}$ level (5) on the issue. It has been found that the academic studies including journals are in higher no. (19) than the others in the category. The report, book and non-academic studies were carried out from different I/NGOs in Nepal on the subject matter which were only 12 in numbers.

In academic researches with university, there seemed high contribution from the scholars of Nepal. A total of 9 studies were conducted by Nepali scholars on the subject matter whereas only three foreigners with foreign universities have done the studies. Most of the Nepali scholars (5) have done the studies with the affiliation of international universities of abroad rather than national university. From national university, only Kathmandu University affiliated scholars have done studies on the thematic subject. None of the studies were carried out by foreigners with the affiliation of national university on the subject matter.

\section{Methodological Approaches of the Studies}

It has been found that majority of studies (18) had applied qualitative methods followed by mixed (7) and there after quantitative (6). Minimum no. of studies was carried out from quantitative approach.

In qualitative approach, the tools were used as document review, observation, interview, focus group discussion, observation, policy review, ranking line, discussion, compilation, literature review and case study.

In quantitative approach, questionnaire survey and data compilation were used. Similarly, in mixed method both quantitative and qualitative tools specially unstructured observation, semi structured interview, FGD, questionnaire survey, document review, consultation, discussion, school survey, KII, case study etc. were used.

There were a total of 12 researches which were from academic level ( $\mathrm{PhD}$, Mphil, Masters) research sphere. It has been found that all the available researches have applied separate theory on their own to carry out the researches. The applied theories were constructionist, disability, ecological system \& dysontogenesis, Giddens' structure-agency, inclusive education, inclusive education $\&$ education for all, pedagogical discourse and alternative models of teaching-learning, positioning theory, theory of access and inclusion, interpretivism, and theory of Planned Behavior.

The paradigms/traditions of the study were non-positivist and post-positivist basically for qualitative and quantitative researches respectively. In non-positivist paradigm, 9 researches were found with 6 different angles. There were four researches carried out from the angle of interpretive whereas other 1-1 research was carried out with the angle of ethnographic, pragmatism, social constructionist, social constructionist and interpretive and transcendental phenomenology.

It has been found that majority (5) of researches were carried out through exploratory design followed by explanatory (3). The quantitative researches were carried out through descriptive and inferential analysis where Likerd scale and logistic regression analysis were used. The convergence parallel design was also used by one research.

Through methodological approaches, it has been found that most of the researches were carried out in qualitative research based worldviews. Minimum researches were carried out from quantitative research based worldview. It may be because that the selection of topic and its needed gravity of analysis demanded to go basically for qualitative and mixed research approach thereby theory, paradigm and design were set accordingly.

\section{Major Findings of the Studies}

To figure out major gaps of the studies, all the available studies were reviewed also from its major findings. Most of the studies have their own areas, so the findings were also separated in terms of children with disabilities, inclusive education and disability as a whole. The major findings of the compiled studies were separated in 5 categories (Academic, non-academic, report, book and journals) accordingly the types of studies.

\section{Findings of the Academic Researches}

There is less effective inclusive pedagogy within the available policies on inclusive education in Nepal. The pedagogical approaches are lapsed due to several factors like ineffective teachers, less inclusive practice in the schools, lack of coordination of community and schools, and minimally available financial resources. Social factors like social beliefs and values, unavailability of resources and ignorance including the negative approach and attitudes of teachers are also vitally important to contribute to ineffective inclusive education [5].

In line with the findings, there are contradictions in contains of policies in Nepal which are more inclined to the medical approach of disability. There is contradiction on government and society perspectives on disability where the society believes that disability is because of the evil deeds of the particular persons who will automatically contribute to discrimination, stigmatization, segregation and eventually exclusion from the society itself. The negative attitudes of teachers and parents are found negative towards disability which is affected by sociocultural ideology, barrier in texts and curriculum, and confusing policies [6].

Talking about the teachers' attitude towards inclusive education, it is clarified that both general and special education teachers are found to have positive attitudes regarding inclusion for students with disabilities. It 
revealed that there are different significant influencing factors such as teacher type, age, gender, education levels, coursework, and residence on determining teachers' attitudes towards inclusive education [7].

Generally teachers feel higher social pressure to practice inclusive education for students with intellectual disability (SWID) also. Teachers seem to be minimally positive about the notion of providing inclusive education to SWID. Similarly, the intention of teacher to practice inclusiveness in classrooms increases with their knowledge about intellectual disability. Further, the intention of teachers to practice inclusive classroom is associated with teachers' expectation from the SWID rather than their knowledge about intellectual disability [8].

From girls' disability perspectives, the girls with disabilities (GWDs) were found diligent to maintain their educational status in comparison to other peers. On available structures, they were struggling to ensure their better future and were ready to go ahead for their better life. Thus, schooling is therefore equated with their change in the lives. However, it is needed to provide alternative/differentiation curriculum for the children in providing fair opportunity to right-based education [9].

Another research revealed that there are pros and cons for the visually impaired girls when talking about integrated education. By studying together with other general students, there is an opportunity to prove them and create a kind of competitiveness. However, this has been a barrier as the approach is "one size fits all" blanket. This has additionally led some visually impaired girl students to become socio-culturally disabled to their already prevalent disability. The unavailability of adequate facilities do not lower the commitment of the students to seek their education and become self-reliant in future [10].

In visual impairment, the quality of teaching learning activities will be determined on the available motivation and rewards for teachers who worked in the inclusive classrooms. There were dissatisfied available in the schools where the adoption of modern technologies for teaching learning was almost not used even if they existed as school supplies. Teachers' motivation, their awareness about the existing policies and continued training to teach in an inclusive classroom are the rewarding approach or working in a different classroom setting were the major issues of the teachers [11].

Another research revealed that there is an insignificant relationship between sex and inclusion in education and employment. The analysis showed that the involvement of male in all indicators of political inclusion as well as in social inclusion is higher than female. However, for females the odds of being involved in disability organizations, political parties, opinions giving in political meeting, involvement in community meeting and volunteering work is more as compared to males [12].

The interacting effects of contextual factors vary for each individual child living with disability, while organizational factors have universal effects due to the interacting nature of these factors. The illumination of the complexity is an opportunity to develop strategies to resolve the current barriers to inclusion in Nepal. This action is critical to ensuring increased numbers of young children with disabilities access early intervention and education programs that support their holistic development and offer access to opportunities that education affords others in Nepal [13].

Access to school is another issue of the children with disabilities. Access to schools differs among disabled children: the availability and accessibility of schools for deaf children is sufficient, while the availability of schools for blind and intellectually disabled children is doubtful. Most children with low vision and a hard of hearing impairment have the possibility to attend regular schools in their local villages. A school for children with multiple impairments is lacking in Baglung district. There is an interrelation of accessibility, affordability and availability, because the location of schools, income of parents and existing (special) schools affect each other. However, income as an independent factor does not play a decisive role on school attendance due to free education for disabled children. In addition, the attained educational level of parents and their caste origins are also not direct related to school attendance of disabled children [14].

There are three limitations to apply inclusive education strategies; a lack of coordination between stakeholders; government inefficiency in a time of political upheaval as the country transitions to a federal republic, and a tendency for education stakeholders to frame inclusion as primarily a socio-economic issue to the neglect of other confounding factors [15].

In Nepal the discussion over disability is based on different aspects on the context that has shaped the overall perspectives and its principle. Here, the inclusion is understood ideologically rather than actual practice. There are lapses on its proper practice. Basically, the policy and practice share the ideas within the periphery of social and right outcome approach but the problems are differently interpreted [16].

\section{Findings of the Non-Academic Researches}

The access gap is the major problems for the children with disabilities, poor, remote, low caste families and ethnic minorities. The number of school children with disability is estimated 179,000 in Nepal. There are numerous factors that contribute to the systematic hurdles to the education of children with disabilities. There are also demand based factors like low level of awareness among parents, communities and low level of capacity of school management committee including parent associations to curtail to receive quality education by such children [17]. 
Similarly, there are other important factors for good life of the children with disabilities including their families. The factors like physical and mental health including empowerment and independence levels are crucial [18].

A baseline study of children with disability revealed that chronic factors in achieving adequate water, sanitation, hygiene, nutrition, healthcare and prevention of disease are a major cause of disability in Nepal. Disability has the casual consequence of social exclusion and if it intersects with other forms of marginalization and discrimination, becomes increasingly hampering on daily lives [19].

\section{Findings of the Different Reports}

In Nepal, disability is seen as an individual sin activity in the past. There is availability of policies and legislatures to preserve the rights of disabled people, local perceptions are still stagnant. The stagnation is there due to cultural beliefs, low level of awareness and problems at local level education [20].

The school environment is not properly accessible to the children with disability even if there are available policies and procedures on child-friendly and inclusive education managed by the government. This is simply a denial to the right to education of the children. There are a lot of barriers which curtail the learning needs of disabled children in schools. The barriers are physical, communication, attitudinal and curricular ones. The physical barriers include not availability of ramps and disabled friendly toilets; communication barrier includes no proper sign language and braille teaching materials. The attitudinal barrier is the negative attitude of the teachers [21].

There is not equal form of disability in the districts of Nepal. The per square kilometer disability rate is 10 persons, which seems to be very critical from disability point of view. In Kathmandu alone, 2000+ deaf/hard of hearing persons are there. The distribution of persons with deaf-blind in all development regions of Nepal not seemed obvious differences [22].

It is found that some resource classes set for children with disabilities are being operated beyond the norms of inclusive education. It is found that there are some obstructing factors for the admission, retention and promotion of children with disabilities in classrooms [23].

In development programs of Nepal, the issue of disability has not been properly and appropriately included. However to some extent, it has been strengthened. The movement of disability has not been able to strategize or promote for its mainstreaming or positioning in socio-political development agenda in line with the rights of persons with disabilities [24].

\section{Findings of the Published Books}

General people believe that persons with disabilities cannot gain anything from education and they cannot contribute to the labor economy including families and entire nation. However, this assumption is totally wrong [25].

Other books just have the compilation on provisions, strategies, guidelines and working procedures including the status of education, inclusive education definition, practices, inclusive education for disabled children, definition of disability classifications, acts and polices regarding disability and inclusion etc., [26].

\section{Findings of the Journal Articles}

Regarding disability, Nepal has enough polices however there is sensitive issue in terms of its execution. The governance part is also weak in the organizations who are working on the issue of disability. Due to lack of responsibility, accountability and transparency the existence of polices is in shadow area. Different aspects of disability are not illustrated systematically which has always impacted to the lives of persons with disabilities in Nepal [27].

It seems that the government of Nepal has supported the rigid and structured schooling. The program for such disabled children is still a matter of concern that contributes to transhumance communities but they will miss out the provided opportunities as per policies which is simply the opportunity costs for attending schools. The policy documents could not have addressed the seasonal migrants' lifestyle of Khumbu Sherpas and their needs for education. This indicates that education of these communities is not appropriately inclusive, meaning that not being able to address cultural/geographical variations and acknowledge the diversity of the nation [28].

There are mixed factors of individual, family, school, community and policy to augment challenges to inclusion. Major factors are the attitude towards education of disabled children, lack of resources in the schools to carry overload of inclusive education and the alarming factors of poor, poverty and deteriorated health [29].

It is found that there is a pure correlation between years of schooling and the likelihood of obtaining a full-time job. It is found that there is low chance of employment for physically disabled but if they employ there is high satisfaction of job among them. It is found that there is a need of more investment in education of persons with disabilities so that it will be helpful for them to enter in labor market [30].

There is positive correlation between teachers' years of experience and their appropriate teaching style as per the needs of visually impaired students. Longer years of experience will greater change in the teaching style. The significant relation exists those who use black or white board. There were negative correlations on teachers' age and residence with their teaching style related decision. It would be double standard adjustment if not providing 
favorable environment to the children by determining the principle of cost effectiveness for equality and quality education of the children with disabilities and that is even ignorant of their further needs. Resource constraint environment should not be included if we want to provide quality and quality education to such children [31].

The education opportunity as per the treatment of integrated education for the education need of children with disabilities is the current concern. In Nepal, there seems inclusion in a half way as special needs education is availed [32].

There is a minimum research in the field of children with disabilities. It is very crucial to know how the family members will manage and care their disabled children with the priorities and limited supports. There are prohibition costs, lack of proper facilities, low skilled health service providers and physical constraints as highlighted by WHO to hinder the healthy life style of persons with disabilities. There is a need of more information regarding health needs of disabled people to narrow the healthcare gaps [33].

\section{Research Gaps in the Studies}

Through the review of the studies from its methodological as well as the key findings, it can be said that there were some good studies carried out in the field of inclusive education, children with hearing impairments and disability as a whole in Nepal. However there is still gap in producing no. of studies in the field of inclusive education, children with disabilities and disability as a whole, considering the acute and vulnerable situations of disabled children in Nepal.

From methodological perspectives, it has been found that there were minimum studies carried out from quantitative approach. The subjectivity of the subject matters is somehow fulfilled (though the available paradigms are not fully accustomed) but there is gap in determining and checking the facts from objectively analyzed findings.

The key findings of the studies have shown that there are huge gaps in practices of disability focused inclusive education though the policy and procedural gaps are also existing in the area. The right outcome approach is not considered minutely in implementing inclusive education in Nepal. It is found that there are different determining factors contributing to the success and failure of inclusive education but solely and critically the attitude of teachers, who is the main implementer of inclusive education, is the main barrier to implement it properly considering the diverse forms of disabilities. The contextual and organizational factors of inclusive education are not dealt with adequately in Nepal. It is found that inclusive education phenomenon is considered as integrated education, thus having created even more challenging atmosphere to the children with disabilities to cope with the situation. Thus, there is research gap to know on what extends the atmosphere of schools will hamper to the education of disabled children. The problems and challenges to implement inclusive education are not dealt minutely through the set indicators of inclusive education in Nepal. Different studies have indicated that there are different factors which will determine the implementing status of inclusive education. However, the major determining factor as the perceptions of teachers that also include attitude, in implementing the inclusive education were not analyzed objectively.

None of the studies were focused on dealing with the case and severity of children with hearing impairment though there were studies available focusing on visually impaired, girl impairment, physical and intellectual disabilities. There is research gap in finding how the main implementers (teachers) feel to implement the practice of inclusive education in Nepal. The theoretical gap has also been figured out. For the study of inclusive education and disability, the theory of inclusive education and educational will have inclination. Theoretically, the inclusive education and educational theory is linked for the paper. The inclusive education and educational theory has the post-modernism paradigm where the social construct of disability in the perspective of right-outcome approach was accorded.

The theory has the strategy of inclusiveness in classroom. A paper presented in La Trobe University, Bundoora, Vic., Australia [34] argues that inclusive education and educational theory are related with the democratic theory which has seven critical constructs or attributes as, the nature of educational authority; the ordering and inclusiveness of membership; the determination of important knowledge; the definition and availability of rights; the nature of participation in decisions that affect one's life; the creation of an optimum environment for learning; and equality.

The theory includes democratic authority, inclusiveness and democratic classroom, the democratic curriculum, student rights, the nature of participation in decisions that affect one's life, establishing optimum environments for learning, and equality. In the same paper, it has been argued that the above mentioned things are the democratic requirements in the classrooms which are expected by inclusive education. These will determine whether the school and classroom are able to become inclusive or not. The envisioned goal of democratic theory in education is that all students, upon completion of secondary schooling are capable of fulfilling the requirements of an informed, active, and responsible democratic citizen. Thus, from this construct of democratic theory, there is huge gap in Nepali context.

Some journals have tried to review the policy available in disability sector. However, there is gap in identifying whether the policy is the main hurdle to implement the inclusive education properly in Nepal. Other journals were 
carried out from different aspects of disability but are not adequate enough, considering the severity and vulnerability of the sector. Some books, reports and non-academic researches were published but seem not adequate enough considering the diverse forms of disabilities in Nepal. There is huge room to promote R \& $\mathrm{D}$ of inclusive education in Nepal.

These indicated research areas are the major gaps figured out by this study. These areas are the probable research areas on the themes. Those who are working, studying and practicing in the field of education and basically the education of disabled children; these are the major angles of studies.

\section{Conclusions}

Through this study it is found that there are minimum studies carried out in disability perspectives inclusive education in Nepal. Methodologically some sound studies are carried out from academic sector but these are not adequate. Nepal has categorized disability in 7 categories (Physical, visual, hearing, vision/hearing, speech, mental and multiple). Out of these, the specific angle to particular disability is minimally given and it is found that none of the studies were ever carried out focusing on children with hearing impairment in Nepal. Even the international researchers have contributed to the field but there is a need of more studies from academic and non-academic sectors to implement the available policies and procedures effectively. Different theories were used for academic level researches basically the constructionist, disability, ecological system \& Giddens' structure agency, inclusive education, education for all, pedagogical discourse etc. If we talk about the disabled children's education, inclusive education concept is paramount important worldwide but from that theoretical perspective minimum researches were carried out. Methodologically, there were found more qualitative and mixed researches in the study theme and there seems a dearth of quantitative studies in the field. Hence, there is a need of adequate studies from quantitative approach also so that the objective reality of the subject matter can be unfolded properly to address the acute problems and challenges of children with disabilities in Nepal.

The studies have indicated that there is a huge contradiction between policy and practice of inclusive education in Nepal. To minimize the gaps and ease the implementation of inclusive education, there is a need of adequate study, prioritizing the research and development in the field. Even though there are a lot of I/NGOs working in the sector, minimum studies were carried out and less no. of reports separately considering the major categories of disabilities were issued. So, these sectors are the areas of initiations by prioritizing $\mathrm{R} \& \mathrm{D}$ on disability perspectives inclusive education in Nepal.

\section{REFERENCES}

[1] MH. Rioux. When myths masquerade as science. In L. Barton \& M. Oliver. Disability Studies: Past, Present and Future. Leeds: The Disability Press, 1997. https://disabilitystudies.leeds.ac.uk/wpcontent/uploads/sites /40/library/rioux-chapter7.pdf.

[2] Constitution of Nepal, 2015

[3] United Nations General Assembly. United Nations Convention on the Rights of Persons with Disabilities (CRPD), 2006. https://www.un.org/esa/socdev/enable/right s/convtexte.htm.

[4] Department of Education (DoE). Inclusive education policy for persons with disabilities, 2016.

[5] NP. Regmi. Inclusive Education in Nepal from Theory to Practice. PhD Thesis, Ludwig-Maximilians-University, Munich, 2017. https://edoc.ub.unimuenchen.de/20510/7/Re gmi_Narayan_P.pdf.

[6] MP. Thapaliya. Moving towards inclusive education: How inclusive education is understood, experienced and enacted in Nepali higher secondary schools. PhD Thesis, University of Canterbury, New Zealand, 2018.

[7] S. Aryal. Teachers' attitude towards inclusive education in Nepal. PhD Thesis, Graduate School of Daegu University, Korea, 2013.

[8] S. Shrestha. Teachers' attitude towards inclusion of students with intellectual disability in community schools. Mphil Dissertation, Kathmandu University, Nepal, 2017.

[9] BBS. Thapa. Schooling of girls with disability: A phenomenological study of Nepali girls. PhD Thesis, Kathmandu University, Nepal, 2012.

[10] P. Shrestha. Exploring the learning experiences of girls with visual disability: A case study approach. Mphil Dissertation, Kathmandu University, Nepal, 2019.

[11] M. Thapa. English language teaching practices for visually impaired students: An ethnographic study. Mphil Dissertation, Kathmandu University, Nepal, 2017.

[12] B. Adhikari. Social inclusion of people with disability living in disability centers in Kathmandu, Nepal. MA Thesis. Oslo and Akershus University College of Applied Sciences, Faculty of Social Sciences, 2015.

[13] D. Dawadi. Inclusion of children living with disability in early childhood education and development programs in Nepal: Construction of a stakeholder informed framework. PhD Thesis, Flinders University, Adelaide, South Australia, 2019.

[14] AS. Oosterlee. The accessibility to basic education for disabled children in Baglung district, Nepal. Master Thesis, Utrecht University, the Netherlands, Plan Nepal, 2012.

[15] S. John. Inclusion for all? An analysis of inclusive education strategies for marginalised groups in Nepal. Master Thesis, Graduate School of Social Sciences University of Amsterdam, 2018. 
[16] L. Brandt. The inclusiveness of society for children with disability in Nepal. Master Thesis, Maastircht University, Faculty of Health, Medicine and Life Sciences, Netherlands. Karuna Foundation, 2015.

[17] National Institute for Research and Training (NIRT). Nepal education sector analysis. Kathmandu, Nepal, 2017.

[18] TI. Mol, W. Brakel, S. Merel. Children with disability in Nepal: New hope through CBR? Vrije Universiteit, Amsterdam, Netherlands, Karuna Foundation Netherlands, Karuna Foundation Netherlands, 2014

[19] PF. Paula Frederica Hunt, N. Poudyal. Of children with disability. UK AID, International Disability Alliance, 2019.

[20] MP. Thapaliya. A report on disability in Nepal. Australian Himalayan Foundation (AHF) Sydney, Australia, 2016.

[21] Human Rights Watch (HR). Futures stolen barriers to education for children with disabilities in Nepal. USA, 2011.

[22] Disability Research Center. Disability atlas of Nepal. School of Arts, Kathmandu University, 2016.

[23] DoE. Analyzing educational status of children with disability and identifying critical intervention to promote their enrollment, retention and success in schools. Dynamic Institute of Research and Development (P) Limited, Kathmandu, 2014

[24] E. Shrestha, A. Nilsson. Mainstreaming disability in the new development paradigm. Norwegian Agency for Development Cooperation, 2012.

[25] K. Lamichhane. Disability, education and employment in developing countries. Cambridge University Press, 2015.

[26] RCRD. Population of persons with disabilities in Nepal, 2012.

[27] R. Baral. Historical policy review on disability. Research Nepal Journal of Development Studies, Vol. 1, No. 1, pp.
73-82, 2018. https://doi.org/10.3126/rnjds.v1i1.21276.

[28] S. Basnet, M. Banskota. Inclusive education for transhumance groups in himalayas: Educational policy challenge for Nepal. Journal of Education and Research, Vol. 2, pp. 26-29, 2010. https://doi.org/10.3126/jer.v2i0.7619.

[29] LM. Banks, M. Zuurmond, A. Monteath-van Dok, J. Gallinetti. Perspectives of children with disabilities and their guardians on factors affecting inclusion in education in rural Nepal: "I feel sad that I can't go to school". Oxford Development Studies UK, Vol. 47, No. 3, pp. 289-303, 2019. https://doi.org/10.1080/13600818.2019.1593341.

[30] K. Lamichhane. The Nexus between Disability, Education, and Employment: Evidence from Nepal. Oxford Development Studies, Vol. 42, No. 3, pp. 439-453, 2014. https://doi.org/10.1080/13600818.2014.927843.

[31] K. Lamichhane. Teaching students with visual impairments in an inclusive educational setting: A case from Nepal. International Journal of Inclusive Education, Vol. 21, No. 1, pp. 1-13, 2017. https://doi.org/10.1080/13603116.2016.118 4323.

[32] M. Sugimura, M. Takeuchi. Rethinking implications of inclusive and special needs education in the context of Nepal. USJI Seminar, Washington DC. Sophia University, JICA Research Institute, 2017. http://www.us-jpri.org/wp/wp-con tent/uploads/2017/03/USJI_Week_FebMar.2017-Event6-Su gimura and Takeuchi.pdf

[33] M. Banskota. Nepal disability policy review. Disability Research Center, School of Arts, Kathmandu University, 2011.

[34] T. Knight. Inclusive education and educational theory, inclusive for what?, 1999. Trobe University, Bundoora, Australia. Paper presented at the British Educational Research Association Conference, University of Sussex, at Brighton. Retrieved from http://www.leeds.ac.uk/educol/do cuments/000001106.htm. 